\title{
Application of Power Electronic Circuitry for Elimination of Flywheel in Process Machines
}

\author{
Vasant Jape $^{1}$, Hiralal Suryawanshi ${ }^{2}$, Jayant Modak ${ }^{3}$ \\ ${ }^{1}$ Department of Electrical Engineering, Govt. College of Engineering, Amravati (M.S.), India \\ ${ }^{2}$ Department of Electrical Engineering, Visvesvaraya National Institute of Technology, Nagpur (M.S.), India \\ ${ }^{3}$ Dean (Research \& Development), Priyadarshani College of Engineering, Nagpur (M.S.), India
}

Email address:

Jape.vasant@rediffmail.com (V. Jape)

${ }^{*}$ Corresponding author

\section{To cite this article:}

Vasant Jape, Hiralal Suryawanshi, Jayant Modak. Application of Power Electronic Circuitry for Elimination of Flywheel in Process Machines. American Journal of Electrical Power and Energy Systems. Vol. 8, No. 2, 2019, pp. 50-55. doi: 10.11648/j.epes.20190802.12

Received: February 16, 2019; Accepted: March 25, 2019; Published: April 22, 2019

\begin{abstract}
It is felt highly probable to eliminate flywheel from the design of any process machine in general and for process machines with a certain demand torque characteristics in particular. It is felt that by proper interfacing of power electronic devices this may be possible. Elimination of flywheel from process machines helps reducing torsional vibrations in the power transmission system of any process machine. This should reduce fatigue in the components of power transmission system thereby prolonging equipment functional failure. Down time will be much less and profit earnings through uninterrupted production would be high. This paper proposes a convenient power electronic circuitry with reasonable control approach for the flywheel replacement of an induction motor for which it is necessary to generate supply torque at motor shaft exactly equal to demand torque. To meet this requirement, demand torque characteristic is sampled at $25 \mathrm{msec}$. In proposed solution to this problem, the torque requirement at every sample is met by adjusting the firing angle of thyristors which in turn adjusts the supply voltage at motor terminals. Depending on supply frequency the sampling period for demand torque characteristic may be varied. The present paper has a focus of evolving the details of functional feasibility of this concept only.
\end{abstract}

Keywords: Flywheel, Demand Torque Characteristic, IGBT'S, Induction Motor

\section{Introduction}

Most part of electrical power system are influenced by substantial power fluctuations mostly arising out of fluctuations in load on industrial drives like rolling mill and planning machine etc. [4-6]. These drives during peak load period draw heavy current from supply which causes objectionable voltage sag in the system which may damage the connected equipments. To smooth out these fluctuations, process of load equalization is used in which energy is stored during interval of light load and released during interval of peak load [1, 7]. Commonly used technique for this is application of flywheel [8] in which abundance energy produced from the supply during light load period is used to accelerate the flywheel thereby storing energy in form of kinetic energy. During peak load period, flywheel decelerates and hence stored energy is used to supply part of the load thereby reducing burden on supply that minimizes the load fluctuations $[9,10]$. This technique of mounting flywheel on motor shaft is obviously suitable only for non-reversible drives $[12,13]$. Additionally, if the transient time of the drive is expanded, a flywheel can't be mounted on the motor shaft in factor speed and reversible drive [14, 15]. The advantages of flywheel energy storage system are more lifespan, almost negligible required upkeep, ecologically agreeable and less life cycle costs. [16, 17]. However disadvantages associated with FES are torsional oscillations, equipment failure, and financial losses. The equipment failure is due to fatigue of mechanical power transmission and the financial losses are due to the frequent downtime [18-19].

Figure 1 describes an arbitrary demand torque characteristic of any process machine. This can be estimated based on cycle time of operation, process resistance and inertia resistance. These can be detailed based on intended 
operation and proposed details of partial mechanical design $[1,2,6]$. It is evident from Figure 1 that crank speed of input shaft of the process machine say it is 30rpm. Complete cycle of operation of the process unit should be 2 sec. getting completed in one rotation of the input link of the process machine and speed of the input crank must be $30 \mathrm{rpm}$.

Figure.1 shows that demand torque varies with time but usually motor cannot generate similar. Supply torque characteristic. Hence the flywheel is required to make up for the difference of the torque in sections $\mathrm{AB} \& \mathrm{CD}$ of time axis. It is known that flywheel will decelerate during intervals $\mathrm{AB} \& \mathrm{CD}$ whereas it will gain speed during intervals $\mathrm{OA}, \mathrm{BC}$, DE sections of time axis.

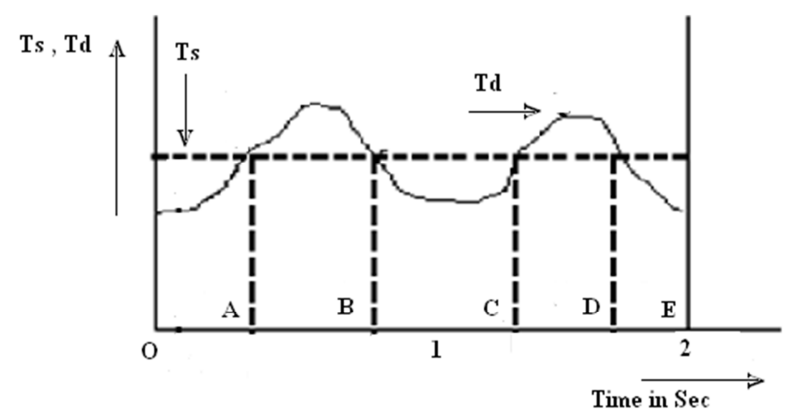

Td-Demand Torque Characteristic ; Ts - Supply Torque Characteristic

Figure 1. Arbitrary TorqueTimecharacteristic.

\section{Flywheel Energy Storage System}

Figure. 2 describes the schematics of an arbitrary process unit along with usual mechanical power transmission system for torque amplification and speed reduction .Pulley D2 is a flywheel cum power transmission pulley. The portion of the system between D2 and process unit is subjected to severe torsional vibrations and associated fatigue damage.

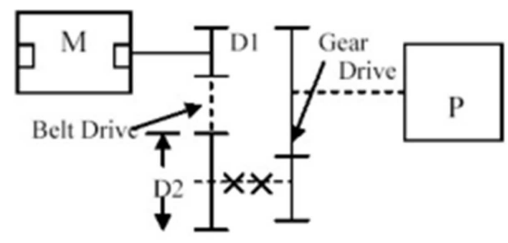

$$
\begin{aligned}
& \text { P-Process Unit M-Motor D1-Driving } \\
& \text { Pulley }
\end{aligned}
$$

Figure 2. Schematics of an Arbitrary Process Unit, Mechanical Power Transmission \& Three phase Induction Motor.

\section{Proposed Solution}

With advent in power electronics and drives [3] it is felt that it will be possible to generate supply torque at motor shaft exactly same as to demand torque with only difference of instantaneous generated torque values would be $1 / 30$ th of demand torque of process unit input shaft. The expected supply torque characteristics would be as shown in Figure 3.

As supply frequency is 50 cycle per second, the time for one cycle of three phase supply is $20 \mathrm{~ms}$. So if we divide
$2000 \mathrm{~ms}$ in equal duration of $20 \mathrm{~ms}$, it will give hundred time intervals. For every such time interval, it is necessary to decide Ts-time curve. This for $2^{\text {nd }}$ section (from $20 \mathrm{~m} \mathrm{sec}$ to $40 \mathrm{~m} \mathrm{sec}$ ) is as shown in the Figure 3 by portion $\mathrm{AB}$ of supply toque characteristics.

Corresponding to the portion $\mathrm{AB}$, the voltage necessary to be imposed across stator of motor can be decided by the following procedure: Starting torque variation of an induction motor versus slip is as under

$$
V_{1}^{2}=\frac{S \omega_{s}}{0.3 R_{2}}\left(R_{1}+\frac{R_{2}}{S}\right)^{2}+\left(X_{1}+X_{2}\right)^{2} T
$$

where

$\mathrm{V}_{1}=$ Impressed voltage per phase

$\mathrm{R}_{1}=$ Stator resistance per phase

$\mathrm{R}_{2}=$ Rotor resistance per phase referred to the stator

$\mathrm{X}_{1}=$ Stator reactance per phase

$\mathrm{X}_{2}=$ Rotor reactance referred to the stator referred to the stator

$\omega_{\mathrm{s}}=$ synchronous angular velocity.

$\mathrm{T}=$ generated torque.

$\mathrm{S}=$ Slip

In the view of Figure 3, $\mathrm{T}_{\mathrm{st}}$ which is equal to $\mathrm{T}$ in equation (I) canbe transformed as a function of time, thus variation of $\left(\mathrm{V}_{1}\right)^{2}$ as a function of $\omega_{\mathrm{s}}, \mathrm{R}_{2}, \mathrm{X}_{2}$ and time $\mathrm{t}$ can be obtained. This precipitates the desired variation of impressed voltage across the stator versus time.

It is possible to arrange for supply voltage variation as would be obtained following the procedure given above for second section of time axis of Figure 3 by approximately adjusting firing angle of two IGBTS necessary in the circuit to be impressed between supply terminals and motor terminals as shown in Figure 4. A special firing circuit will have to be designed, for varying firing angle in every $20 \mathrm{~ms}$ in a definite sequence. For maintaining the simplicity of schematics the firing circuitry for all three phases is not shown.

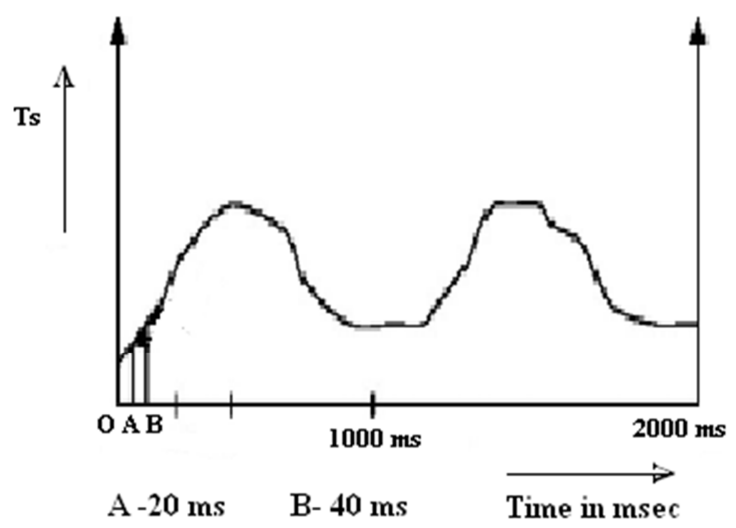

Figure 3. Expected supply torque characteristics.

\section{Simulation}

Computer simulation will be evolved which will give necessary firing angles for the complete cycle of operation of 
a process unit. PC based firing circuit for firing thyristors at required angle will generate required voltage waveform. This simulation is shown in the Figure. 4

\section{Application to a Case Study}

The foregoing is the proposed logic for the procedure to be adopted for implementing this concept to a specific case. APPENDIX $1[4,5]$ details a specific case study in which this application is demonstrated.

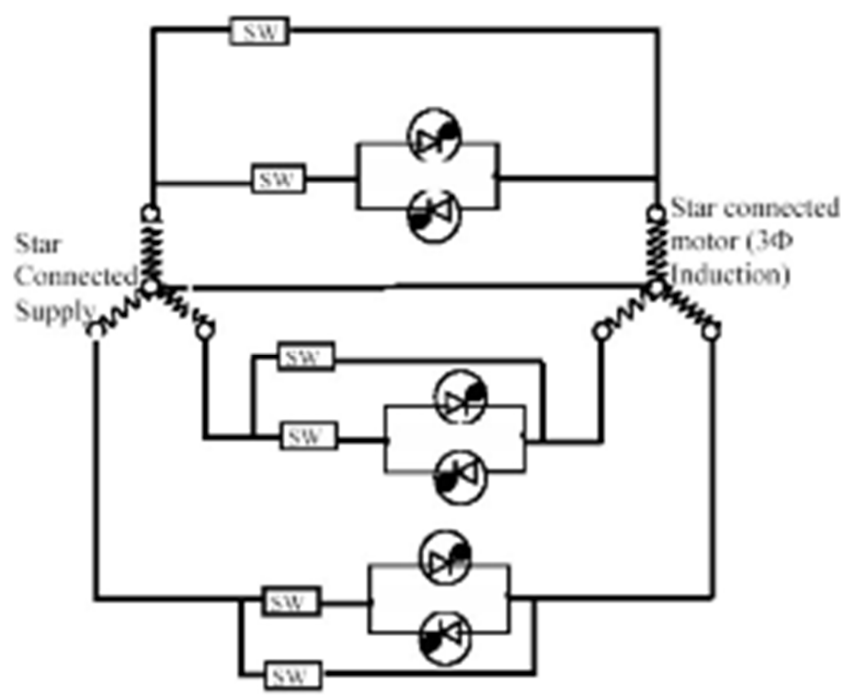

Figure 4. IGBT'S circuit for appropriate firing angle.

\section{Adjustment for Variation in Load}

A separate simulation should be generated for estimating $\mathrm{Td}$ - time curve for variation in the load. This simulation will - precede the one described above under the head simulation.

\section{Overall Interfacing Circuit Between Supply and Motor Terminals}

In View of the details elaborated in Appendix 1 of the case study, it is clear that the two IGBT'S in anti parallel preceded by a frequency converter is necessary only for the portions $\mathrm{AB}$ and $\mathrm{CD}$ of the demand torque characteristics whereas for portion $\mathrm{BC}$ normal supply voltage needs to be impressed across motor terminals. This change over of supply through IGBT'S and directs supply is conceptually possible by a circuit described in Figure 4

\section{Conclusion}

Present paper details the logic of developing the appropriate drive to eliminate flywheel including provision for variation in load. However, it may introduce new problem of torsional vibrations on account of effect, of non firing duration of IGBTS in every cycle. This is on account of considering only the first harmonic of the clipped voltage supply through IGBT'S. A comparative analysis will be obviously required to finally conclude the extent to which this concept of elimination of flywheel would be functionally and economically viable. This aspect is proposed as the further extension of the present development. The present paper has a focus of evolving the details of functional feasibility of this concept.

\section{Appendix}

A Specifications of selected Machine

A process machine comprises of some linkage mechanism as basic mechanical hardware of a process unit.. It is well known that whenever process machine has a linkage as a main processor on account of non linear kinematics of the hardware, demand torque characteristics of the process machine is time variant. Figure 5 describe the demand torque characteristics of the assumed process machine. The demand torque characteristics shows that the average supply torque is $23.8 \mathrm{~N}-\mathrm{M}$ as generated by motor. The total cycle time of the process machine is $2000 \mathrm{~ms}$. Now let the assumed motor be three phase $440 \mathrm{~V}$ induction motor with synchronous speed as $1500 \mathrm{rpm}$. In view of foregoing discussion, the average angular velocity of the input crank of the process unit must be $30 \mathrm{rpm}$. This gives torque amplification from motor shaft to the process unit input shaft of the order of $1500 / 30=$ $50 \mathrm{rpm}$. Thus the supply torque at the process unit input shaft is $23.8 \times 50=1190 \mathrm{~N}-\mathrm{M}$. Hence the $\mathrm{hp}$ demand of the process unit is $\mathrm{hp}=2 \times 3.14 \times \mathrm{NxT} / 4500$ $=2 \times 3.14 \times 30 \times(23.8 \times 50) / 4500=5 \mathrm{hp}$.

B Determination of impressed voltage per phase

As shown in Figure 5 complete duration of $2000 \mathrm{~ms}$ is divided in 80 time intervals each of $25 \mathrm{~ms}$. Impressed voltage / phase to produce supply torque equal to demand torque is estimated using the following equation and is tabulated in Table 1.

$$
V_{1}^{2}=\frac{S \omega_{s}}{0.3 R_{2}}\left(R_{1}+\frac{R_{2}}{S}\right)^{2}+\left(X_{1}+X_{2}\right)^{2} T
$$

where

$\mathrm{V}_{1}=$ Impressed voltage per phase

$\mathrm{R}_{1}=$ Stator resistance per phase

$\mathrm{R}_{2}=$ Rotor resistance per phase referred to the stator

$\mathrm{X}_{1}=$ Stator reactance per phase

$\mathrm{X}_{2}=$ Rotor reactance referred to the stator referred to the stator

$\omega_{\mathrm{s}}=$ synchronous angular velocity.

$\mathrm{T}=$ generated torque .

$\mathrm{S}=$ Slip

Table 1 specifies final outcome of the calculations

C Determination of Firing Angle

For every time intervals of $25 \mathrm{~ms}$ of the portion $\mathrm{AB}$ and $\mathrm{CD}$ of the Figure 1 firing angles for two IGBT'S in a anti parallel per phase is calculated as per the equation (3)given below [2]

$$
\mathrm{V}_{1 m}=\frac{V_{m}}{\pi}\left[\left\{\frac{\operatorname{Sin}(2 \alpha)}{2}+(\pi-\alpha)\right\}^{2}+\left\{\frac{\operatorname{Cos}(2 \alpha)}{2}\right\}^{2}\right]^{\frac{1}{2}}
$$


Where

$\mathrm{V} 1 \mathrm{~m}=$ Voltage of referred torque value

$\mathrm{Vm}=$ Impressed voltage

$\alpha=$ Firing Angle

The calculated firing angle values for every $25 \mathrm{~ms}$ time intervals of the portion $\mathrm{AB}$ and $\mathrm{CD}$ is as shown in Table 1

D Design of firing circuit

It is necessary to design appropriate firing circuit using aproper timer. The details of this firing circuit are not given in the paper.

E Solution for portion BC

For the portion $\mathrm{BC}$ of the demand torque characteristics the demand torque is more than the supply torque. The corresponding slip values for every $25 \mathrm{~ms}$ time intervals are calculated from the Figure 6 In this case supply voltage is assumed to be the normal phase voltage.

Table 2 shows the slip values for all these $25 \mathrm{~ms}$ time intervals of the portion $\mathrm{BC}$ of the demand torque characteristics. From Table 2 it is obvious that the maximum slip is $9.1 \%$. Usually this is a permissible coefficient of fluctuation of speed for some process machine[2].

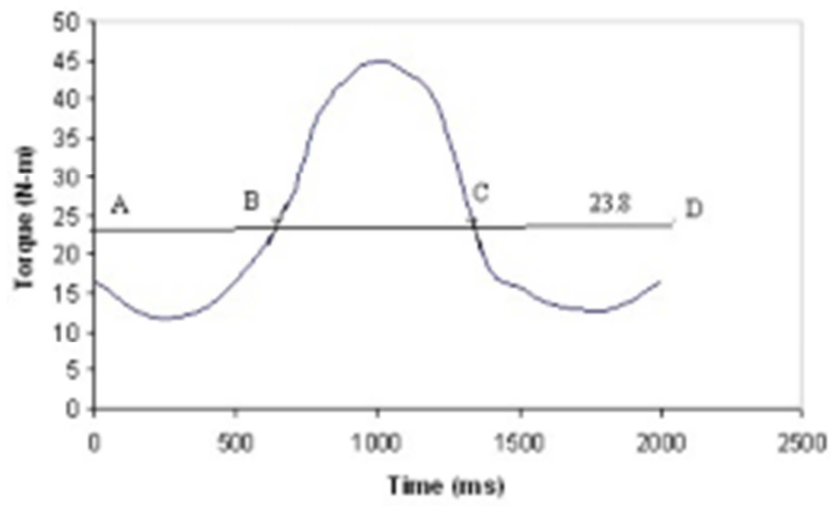

Figure 5. Demand Torque Characteristic of a specified machine.

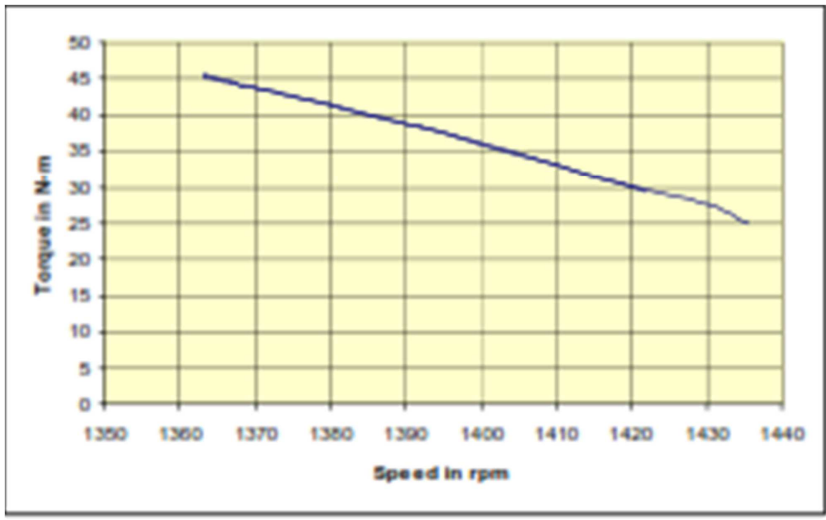

Figure 6. Operating portion of Torque-Speed Characteristic.

F Application to different processes

The proposed concept can be extended to several processes. Two sample cases for application are as follows.

Figure 7 describes a demand torque characteristic of a process machine in which mechanism performing main process is a four bar chain (crank rocker inversion). Process resistance is present during both the strokes of follower.

According to the specifications of a motion program ofa follower one gets total demand torque variation over one cycle of rotation of crank shaft as shown in Figure 7.

The crank shaft speed is assumed to be $300 \mathrm{rpm}$. Assuming mechanical \& electrical efficiencies of the system to be equal to $85 \%$ each, total h.p. demand of the motor comes out to be 4.42 h.p. which is nearly equal 5 h.p.

The way the power electronic circuitry is designed for the demand torque characteristic shown in Figure 2, the same way it can be worked out for the demand torque characteristic shown in Figure 7.

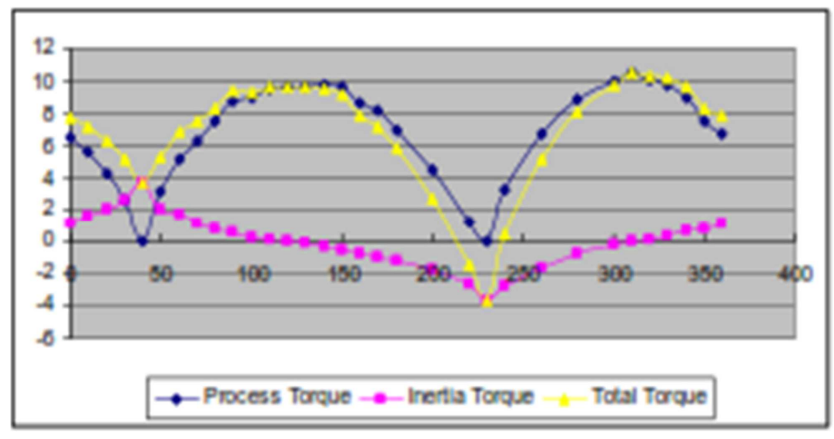

Figure 7. Demand Torque Characteristic of Crank Rocker Inversion.

Figure 8 describes a demand torque characteristic of a process machine in which mechanism performing main process is a combination of a cam follower in series with a slider crank mechanism. Process resistance is present during both the strokes of follower.

According to the specifications of part of the motion program of a follower, one gets total demand torque variation over one cycle of rotation of a camshaft as shown in Figure 8. The camshaft speed is assumed to be $300 \mathrm{rpm}$. Assuming mechanical \& electrical efficiencies of the system to be equal to $85 \%$ each, total h.p. demand of the process unit comes out to be 1.75 h.p.

The way the power electronic circuitry is designed for the demand torque characteristic shown in Figure 2, the same way it can be worked out for the demand torque characteristic shown in Figure 8.

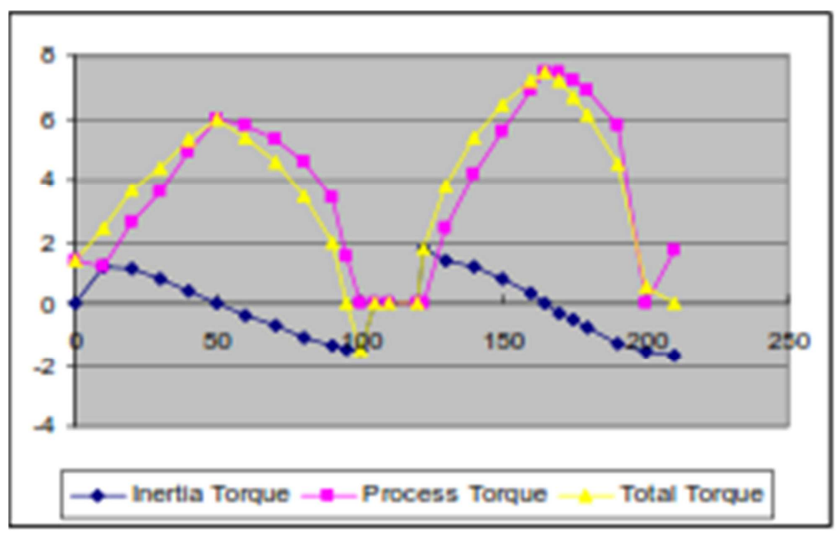

Figure 8. Demand Torque Characteristic of a CAM follower Mechanism. 
Table 1. Firing Angle required to generate given Average torque.

\begin{tabular}{|c|c|c|c|}
\hline Sr. No & $\begin{array}{l}\text { Average } \\
\text { Torque(N-M) }\end{array}$ & $\begin{array}{l}\text { Impressed } \\
\text { Voltage (V) }\end{array}$ & $\begin{array}{l}\text { Firing Angle } \\
\text { (Degree) }\end{array}$ \\
\hline 01 & 16 & 208.43 & 32.9 \\
\hline 02 & 15.5 & 205.15 & 35.4 \\
\hline 03 & 15 & 201.82 & 37.8 \\
\hline 04 & 14 & 194.97 & 42.8 \\
\hline 05 & 13.5 & 191.46 & 45.4 \\
\hline 06 & 13 & 187.88 & 47.9 \\
\hline 07 & 12.5 & 184.23 & 50.5 \\
\hline 08 & 12 & 180.51 & 53.2 \\
\hline 09 & 11.5 & 176.71 & 56 \\
\hline 10 & 11 & 172.82 & 58.8 \\
\hline 11 & 11 & 172.82 & 58.8 \\
\hline 12 & 12 & 180.513 & 53.2 \\
\hline 13 & 12.3 & 182.75 & 51.6 \\
\hline 14 & 12.5 & 184.23 & 50.5 \\
\hline 15 & 13 & 187.88 & 47.9 \\
\hline 16 & 13.5 & 191.46 & 45.4 \\
\hline 17 & 14 & 194.97 & 42.80 \\
\hline 18 & 15 & 201.82 & 37.8 \\
\hline 19 & 15.5 & 205.15 & 35.4 \\
\hline 20 & 16.5 & 211.67 & 30.6 \\
\hline 21 & 17.5 & 217.99 & 26.1 \\
\hline 22 & 18.0 & 221.08 & 23.8 \\
\hline 23 & 19.5 & 230.11 & 17.3 \\
\hline 24 & 21.0 & 238.79 & 11.0 \\
\hline 25 & 22.0 & 244.41 & 6.95 \\
\hline 26 & 23.5 & 252.61 & 1 \\
\hline 53 & 22.5 & 247.15 & 4.9 \\
\hline 54 & 21.0 & 238.79 & 11 \\
\hline 55 & 20.0 & 233.04 & 15.2 \\
\hline 56 & 18.0 & 221.08 & 23.8 \\
\hline 57 & 17.5 & 217.99 & 26.1 \\
\hline 58 & 17.0 & 214.85 & 28.45 \\
\hline 59 & 16.0 & 208.43 & 32.8 \\
\hline 60 & 16.5 & 211.67 & 30.6 \\
\hline 61 & 16.0 & 208.43 & 32.8 \\
\hline 62 & 15.0 & 201.82 & 37.8 \\
\hline 63 & 14.5 & 198.42 & 40.2 \\
\hline 64 & 14 & 194.97 & 42.8 \\
\hline 65 & 13.5 & 191.46 & 43.4 \\
\hline 66 & 13.5 & 191.46 & 45.4 \\
\hline 67 & 13.0 & 187.88 & 47.9 \\
\hline 68 & 13.0 & 187.88 & 47.9 \\
\hline 69 & 12.5 & 184.23 & 50.5 \\
\hline 70 & 12.5 & 184.23 & 50.5 \\
\hline 71 & 12.75 & 186.06 & 49 \\
\hline 72 & 12.75 & 186.06 & 49 \\
\hline 73 & 13.25 & 189.68 & 46.6 \\
\hline 74 & 13.5 & 191.46 & 45.4 \\
\hline 75 & 13.75 & 193.22 & 43.9 \\
\hline 76 & 14.25 & 196.71 & 41.5 \\
\hline 77 & 14.75 & 200.13 & 39 \\
\hline 78 & 15.25 & 203.49 & 36.7 \\
\hline 79 & 15.75 & 206.80 & 34.1 \\
\hline 80 & 16 & 208.43 & 32.8 \\
\hline
\end{tabular}

Table 2. Percentage slip at given Average torque.

\begin{tabular}{|c|c|c|}
\hline Sr. No & Average Torque (N-M) & Percentage slip \\
\hline 27 & 25 & 4.3 \\
\hline 28 & 27.5 & 4.65 \\
\hline 29 & 30.5 & 5.4 \\
\hline 30 & 34.0 & 6.2 \\
\hline 31 & 36.0 & 6.7 \\
\hline 32 & 38.5 & 7.2 \\
\hline 33 & 40.0 & 7.64 \\
\hline 34 & 41.0 & 7.92 \\
\hline 35 & 42.0 & 8.17 \\
\hline 36 & 43.0 & 8.47 \\
\hline 37 & 43.5 & 8.58 \\
\hline 38 & 44.0 & 8.77 \\
\hline 39 & 44.5 & 8.9 \\
\hline 40 & 45.0 & 9.1 \\
\hline 41 & 45.5 & 9.1 \\
\hline 42 & 44.5 & 8.9 \\
\hline 43 & 44.0 & 8.77 \\
\hline 44 & 43.5 & 8.6 \\
\hline 45 & 43.0 & 8.47 \\
\hline 46 & 42.5 & 8.32 \\
\hline 47 & 41.5 & 8 \\
\hline 48 & 40.0 & 7.64 \\
\hline 49 & 38.5 & 7.2 \\
\hline 50 & 37.0 & 6.9 \\
\hline 51 & 34.0 & 6.2 \\
\hline 52 & 29.5 & 5.2 \\
\hline
\end{tabular}

\section{References}

[1] Richard G. Budynas, J. Keith Nisbett,"Shigley's Mechanical Engineering Design”,McGraw Hill, Ed. Ninth, 2014.

[2] Joseph Edward Shigley, John Joseph Uicker Jr., Gordon R. Pennock "Theory of Machines \& Mechanisms", Oxford University Press Ed. Fifth December 2016.

[3] Cyril W. Lander, "Power Electronics", McGraw Hill, London, Ed. Third 1993

[4] M. Wu, X. Cui, and J. Li, "Analysis on Power Loss of the Three-Phase Induction Motor Fed by VVVF under Constant Torque Load", Applied Mechanics and Materials, vol. 635637, pp. 1207-1211, 2014.

[5] I. Alan and T. Lipo, "Induction machine based flywheel energy storage system", IEEE Transactions on Aerospace and Electronic Systems, vol. 39, no. 1, pp. 151-163, 2003.

[6] G. Suvire and P. Mercado, "DSTATCOM with Flywheel Energy Storage System for wind energy applications: Control design and simulation", Electric Power Systems Research, vol. 80, no. 3, pp. 345-353, 2010.

[7] N. Bianchi, S. Bolognani, D. Bon and M. Dai Pre, "Torque Harmonic Compensation in a Synchronous Reluctance Motor", IEEE Transactions on Energy Conversion, vol. 23, no. 2, pp. 466-473, 2008.

[8] R. Weissbach, G. Karady and R. Farmer, "A combined uninterruptible power supply and dynamic voltage compensator using a flywheel energy storage system", IEEE Transactions on Power Delivery, vol. 16, no. 2, pp. 265-270, 2001. 
[9] H. Akagi and H. Sato, "Control and performance of a doublyfed induction machine intended for a flywheel energy storage system", IEEE Transactions on Power Electronics, vol. 17, no. 1, pp. 109-116, 2002.

[10] S. Gurumurthy, A. Sharma and V. Agarwal, "Optimal energy harvesting from a high-speed brushless DC generator-based flywheel energy storage system", IET Electric Power Applications, vol. 7, no. 9, pp. 693-700, 2013.

[11] D. Lin, B. Hou and C. Lan, "A balancing cam mechanism for minimizing the torque fluctuation of engine camshafts", Mechanism and Machine Theory, vol. 108, pp. 160-175, 2017.

[12] Jae-Do Park, C. Kalev and H. Hofmann, "Control of HighSpeed Solid-Rotor Synchronous Reluctance Motor/Generator for Flywheel-Based Uninterruptible Power Supplies", IEEE Transactions on Industrial Electronics, vol. 55, no. 8, pp. 3038-3046, 2008.

[13] M. Khodayari and A. Aslani, "Analysis of the energy storage technology using Hype Cycle approach", Sustainable Energy Technologies and Assessments, vol. 25, pp. 60-74, 2018.

[14] W. Diao, N. Xue, V. Bhattacharjee, J. Jiang, O. Karabasoglu and M. Pecht, "Active battery cell equalization based on residual available energy maximization", Applied Energy, vol. 210, pp. 690-698, 2018.
[15] Y. Tu, K. Cheng, M. Lee and J. Liu, "A Power-Saving Adaptive Equalizer With a Digital-Controlled Self-Slope Detection", IEEE Transactions on Circuits and Systems I: Regular Papers, pp. 1-12, 2018.

[16] Y. Chen, X. Liu, H. Fathy, J. Zou and S. Yang, "A graphtheoretic framework for analyzing the speeds and efficiencies of battery pack equalization circuits", International Journal of Electrical Power \& Energy Systems, vol. 98, pp. 85-99, 2018.

[17] V. Viswanathan and J. Seenithangom, "Commutation Torque Ripple Reduction in the BLDC Motor Using Modified SEPIC and Three-Level NPC Inverter", IEEE Transactions on Power Electronics, vol. 33, no. 1, pp. 535-546, 2018.

[18] M. Nikzad, B. Asaei and S. Ahmadi, "Discrete Duty-CycleControl Method for Direct Torque Control of Induction Motor Drives With Model Predictive Solution", IEEE Transactions on Power Electronics, vol. 33, no. 3, pp. 2317-2329, 2018.

[19] N. Zhao, G. Wang, D. Xu, L. Zhu, G. Zhang and J. Huo, "Inverter Power Control Based on DC-Link Voltage Regulation for IPMSM Drives Without Electrolytic Capacitors", IEEE Transactions on Power Electronics, vol. 33, no. 1, pp. 558-571, 2018. 